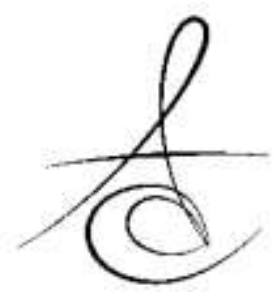

\section{EBEVEYNLERİN SOSYO-EKONOMİK DURUMUNUN VE ORAL HİJYEN ALIŞKANLIKLARININ ERKEN ÇOCUKLUK ÇAĞI ÇÜRÜKLERİNE ETKİSİ}

\author{
THE EFFECTS OF PARENTS' ORAL HYGIENE HABITS AND SOCIO-ECONOMIC \\ STATUS ON EARLY CHILDHOOD CARIES
}

Dr. Öğr. Üyesi Tuğba YíĞìT*
Prof. Dr. Çiğdem KÜÇÜKEŞMEN**

\author{
Makale Kodu/Article code: 4261 \\ Makale Gönderilme tarihi: 06.01 .2020 \\ Kabul Tarihi: 12.06 .2020 \\ DOI : $10.17567 /$ ataunidfd.752020
}

öz

Tuğba Yiğit: ORCID ID: 0000-0002-8742-9031

Çiğdem Küçükeşmen: ORCID ID: 0000-0003-3114-1036

Amaç: Erken çocukluk çağı çürüğü ve sosyoekonomik durum arasındaki ilişkiyi değerlendirmek ve riskli sosyo-ekonomik gruplarda çürük önleme stratejilerinin geliştirilmesine katkı sağlamaktır.

Gereç ve yöntem: Çalışmamıza 3-5 yaşları arasında erken çocukluk çürüğü olan , gönüllü ve rastgele seçilmiş 530 çocuk ve ebeveyni dahil edilmiştir . Ebeveynlerin ve çocukların ağı içi muayenelerinin yapılmış ve ebeveynlere anket formları doldurtulmuştur. Klinik muayenede, çocukların dmfs ve ebeveynlerin DMFT, gingival ve basitleştirilmiş oral hijyen indeks değerleri hesaplanmışır. Sosyo-ekonomik seviyenin belirlenmesinde; eğitim, gelir ve meslek durumu temel alınmıştır. Elde edilen veriler, SPSS yazıım programı ile incelenmiş, ANOVA, Tukey, Ki-kare ve t-test kullanılarak değerlendirilmiştir.

Bulgular: Ebeveynleri memur olan çocukların dmfs değerleri daha düşük bulunurken, ebeveynlerin çalışmadığı ve gelir düzeyi düşük ailelerin çocuklarında dmfs değerlerinin yüksek olduğu gözlenmiştir $(p<0,001)$. Ebeveynlerin eğitim seviyeleri arttıkça, çocukların dmfs değerlerinin azaldığı, diş fırçalama sıklı̆ının arttığı ve fırçalamaya başlama yaşının düştüğü tespit edilmiştir $(p<0,001)$. Gingival ve oral hijyen indeks değerleri 3 olan $(p<0,01)$, haftada 1 kez diş firçalayan veya hiç diş firçalamayan $(p<0,001)$, diş ipi kullanmayan ebeveynlerin ve gargara kullanmayan $(p<0,001)$ annelerin çocuklarında dmfs değerlerinin oldukça yüksek olduğu görülmektedir.

Sonuç: Düşük sosyo-ekonomik seviyedeki çocuklarda diş çürüklerinin önlenmesinin, yüksek sosyo-ekonomik seviyedeki çocuklar kadar başarıı olmadığı görülmüştür. Çocukların rol model olarak aldıkları ebeveynlerinin oral hijyen alışkanlıklarının, çocukların alışkanlıklarının şekillenmesi üzerinde oldukça önemli olduğu düşüncesine varılmıştır.

Anahtar kelimeler: Ağız sağlı̆̆ı, erken çocukluk çağı çürükleri, risk faktörleri

\title{
ABSTRACT
}

Aim: The focused the study is to assess the connection between early childhood caries and socioeconomic status and to contribute to develop strategies for preventing caries in risky socio-economic groups.

Material and methods: Our study conducted with 3-5 years old, 530 children and randomized questionnaires for parents and performing oral examinations of parents and children by the dentist. Mothers of 463 children and fathers of 246 children were examined. In clinical examination, DMFT, gingival and simplified oral hygiene index values of the parents and dmfs index values of the children's were calculated. The datas were analyzed by SPSS software program and assessed with ANOVA, Tukey, Chisquare and t-test.

Results: While the dmfs values of the children whose parents were civil servants were found lower, it was observed that the dmfs values were higher in the parents who did not work and the children of low income families $(p<0.001)$. The dmfs values of children decreased opposite, and frequency of tooth brushing was changed parallel to the educational level of parents. Otherwise, starting brushing was gone to the earlier ages $(p<0.001)$. The dmfs values of the children were very high whose mothers never use oral mouthwash $(p<0.001)$, parents brush their teeth weekly/never and never use dental floss $(p<0.001)$, gingival and oral hygiene index values are $3(p<0.01)$.

Conclusion: Prevention of dental caries in children at low socio-economic level is not as successful as children at high socioeconomic level.

Key words: Oral health, early childhood caries, risk factors

*Uşak Üniversitesi Diş Hekimliği Fakültesi, Pedodonti Anabilim Dalı, Uşak

**Süleyman Demirel Üniversitesi Diș Hekimliği Fakültesi, Pedodonti Anabilim Dalı, Isparta

Kaynakça Bilgisi: Yiğit T, Küçükeşmen Ç. Ebeveynlerin Sosyo-Ekonomik Durumunun Ve Oral Hijyen Alışkanlıklarının Erken Çocukluk Çağı Çürüklerine Etkisi. Atatürk Üniv Diş Hek Fak Derg 2020; 30: 366-72

Citation Information: Yigit T, Kucukesmen C. The Effects Of Parents' Oral Hygiene Habits and Socio-Economic Status on Early Childhood Caries. J Dent Fac Atatürk Uni 2020; 30: 366-72. 


\section{GİRİŞ}

Erken çocukluk çağı çürükleri (EÇÇ), 71 aylık ve daha küçük çocuklarda görülen, enfeksiyöz, bulaşıcı, bebeklik ve erken çocukluk çağı dönemlerinde sık görülen hastalıklar arasındadır. ${ }^{1}$ EÇÇ etyolojisinde beslenme, biyolojik, davranışsal ve sosyal birçok faktör bulunan multifaktöriyel enfeksiyöz bir hastalıktır. Zaman içerisinde kümülatif bir etki oluşturan risk faktörleri bir bütün olarak değerlendirilmelidir ${ }^{2}$

Bireyin sosyo-ekonomik durumu ile genel sağlığı arasında güçlü bir ilişki mevcuttur. Sosyo-ekonomik durumu düşük olan ailelerin çocuklarında diş çürüklerine daha fazla rastlanmıştır. ${ }^{3,4}$ Sosyo-ekonomik seviyenin düşük olması ve erken çocukluk çağı çürükleri (EÇÇ) arasındaki ilişki; beslenmenin kötü olması, uzun süreli emzirme, eğitim seviyesinin düşük olması, oral sağlığa önem verilmemesi, ${ }^{5}$ diş hekimi ziyaretlerinin daha az ve/veya daha geç yaşlarda olması ve sadece diş ile ilgili sorunlar olduğunda gerçekleştirilmesi, diş fırçalamaya daha geç yaşlara başlanması ve dişlerin olması gerekenden daha az fırçalanması ${ }^{6}$ ve annelerin çalışma hayatına erken başlamaları nedeni ile çocuklarla yeterli düzeyde ilgilenememeleri ${ }^{7}$ gibi sebeplerle ilişkili görülmektedir. Konuşulan dil, iletişim, eğitim, sosyalleşme ve toplumun tüm yaşam alanlarına katıım konularında yetersizlik, sağlık bilgilerine ve kitle iletişim araçlarına ulaşımı zorlaştırmakta ve sağlık eğitiminin daha düşük bir seviyede kalmasına neden olmaktadır. Ebeveyn-çocuk-diş hekimi arasında etkisiz bir iletişim meydana gelmekte ve EÇÇ riski artmaktadır. ${ }^{2}$ Ayrıca bu çocukların yaşadığı evlerin eski ve bakımsız olması $\mathrm{da}$, çocuklar için enfeksiyon kaynağı oluşturabilmektedir. ${ }^{7}$ Çalışmamızın amacı, EÇÇ'nin olası sosyoekonomik ve davranışsal ilişkilerini değerlendirmek ve riskli sosyo-ekonomik gruplarda çürük önleme stratejilerinin geliştirilmesine katkı sağlamaktır.

\section{GEREÇ VE YÖNTEM}

Çalışmamıza, Süleyman Demirel Üniversitesi Klinik Araştırmalar Etik Kurulu 09 Temmuz 2015 tarihli ve 136 karar numaralı izni alınarak başlanmışıı. Onamı alınan ebeveynler ayrıntıı bir biçimde bilgilendirilmiştir. Çalışmanın gücünün, 0.05 anlamlılık düzeyi ve 0.75 duyarllıkta \%95 olabilmesi için gerekli olan örneklem sayısının 494 olması gerektiği belirlenmiştir. Çalışmamıza, Süleyman Demirel Üniversitesi Diş Hekimliği Fakültesi Pedodonti Anabilim Dalı Kliniği'ne başvuran, 3-5 yaşları arasında erken çocukluk çürüğü olan, gönüllü ve rastgele seçilmiş ' 255 kız, 275 erkek" olmak üzere, toplam 530 çocuk ve ebeveyni dahil edilmiştir. Sosyoekonomik ve demografik durumun değerlendirilmesi için, ebeveynlerin eğitim seviyeleri 'ilkokul, lise ve üniversite' olmak üzere üç grupta, meslekleri 'işsiz, iş̧̧i, memur, serbest meslek' olmak üzere dört grupta sınıflandırılmıştır. Gelir seviyesi, ailedeki kişi sayısına göre Türkiye İstatistik Kurumu'nun açlık ve yoksulluk sınıları esas alınarak, açık sınıının altındaki gelir değerleri düşük, açlık ve yoksulluk sınırları arasındaki gelir değerleri orta ve yoksulluk sınıının üstündeki gelir değerleri yüksek gelir olarak sınıflandırımıştır. Ebeveynlerin oral hijyen alışkanları; diş fırçalama sıkı̆̆ı, diş ipi ve gargara kullanımı ile değerlendirilmiştir.

Muayeneden bir hafta sonra 98 hasta, klinik gözlemlerin tekrarlanabilirliğini ölçmek amacıyla tekrar değerlendirildi (Kappa:0,90).

\section{Klinik muayene}

Klinik muayene, DSÖ kriterlerine (1977) göre; fotöyde, steril ayna ve sond yardımı ile ünit ışı̆ı altın$\mathrm{da}$, ebeveynlerde DMFT ve çocuklarda dmfs değerleri hesaplanmıştır. Ayrıca ebeveynlerde, gingival ${ }^{8}$ ve basitleştirilmiş oral hijyen indeks ${ }^{9}$ değerleri de değerlendirilmiştir. Elde edilen değerler; ' 0 ' ise $0, ' 0-1$ ' arasında ise 1, ' $1-2$ ' arasında ise 2, ' $2-3$ ' arasında ise 3 olarak gruplandırılmıştır.

\section{Ístatistiksel Analiz}

Tüm değerlendirmeler, SPSS yazılım programı (SPSS-Statistical Package for Social Science, Software Version 23, SPSS Inc., Chicago, IL, USA) yardımıla gerçekleştirilmiştir.

Dmfs değerleri ve klinik özellikler incelendiğinde, sayısı 2'den fazla olan klinik özellikler için (diş fırçalama sıklı̆ı vb.) 'Varyans Analizi Tekniği (ANOVA)' sayısı 2 olan demografik özellikler için (cinsiyet vb.) 'tTesti' uygulanmıştır. 'Tukey Testi' faktörlerin ortalamalarının değerlendirilmesinde kullanılmışı Gruplandırılmış verilerde üzerinde durulan olgulara 'Kikare Test' uygulanmıştır $(p<0,05)$. Devamlı özelliklerde korelasyonun belirlenmesi için ( $\mathrm{dmfs} \mathrm{vb}$.) 'Pearson Korelasyon Katsayısı' kullanıımışıı $(p<0,05)$.

\section{BULGULAR}

Aylık gelir $(p<0,001)$, ebeveynlerin meslekleri $(p<0,001)$, ebeveynlerin eğitim düzeyleri $(p<0,001)$ ile $\mathrm{dmfs}$ değerleri arasındaki fark istatistiksel olarak anlamlı görülmüştür (Tablo 1). Ailelerin aylık gelir düzeyleri arttıkça, çocuklarda gözlenen dmfs değerleri azalma göstermektedir. En yüksek dmfs değeri, annesi 
çalışmayan ve babası serbest meslek sahibi veya işçi olan çocuklarda görülmüştür. Ayrıca, üniversite mezunu olan anne ve babaların çocuklarında en düşük dmfs değerleri görülmüştür.

Tablo 1. Ailenin gelir seviyesi, anne ve babanı eğitim seviyesi ve mesleğine göre ortalama dmfs değerleri

\begin{tabular}{|c|c|c|c|c|c|c|}
\hline & & $\mathbf{N}$ & $\%$ & $\begin{array}{l}\text { Ortalama } \\
\text { dmfs }\end{array}$ & $\begin{array}{l}\text { Standart } \\
\text { Sapma }\end{array}$ & $\underset{\substack{p \\
\text { değeri }}}{p<0,05)}$ \\
\hline \multirow[t]{3}{*}{$\begin{array}{l}\text { Aylık } \\
\text { gelir }\end{array}$} & $\begin{array}{c}\text { Yüksek } \\
\text { gelir }\end{array}$ & 44 & 8,3 & $13,750 \mathrm{~b}$ & 12,1887 & \multirow{3}{*}{0,000} \\
\hline & Orta gelir & 126 & 23,7 & $18,294 b$ & 13,7667 & \\
\hline & $\begin{array}{c}\text { Düşük } \\
\text { gelir }\end{array}$ & 360 & 68 & $21,153 a$ & 14,8568 & \\
\hline \multirow[t]{4}{*}{$\begin{array}{c}\text { Anne } \\
\text { mesleği }\end{array}$} & Memur & 77 & 14,5 & $13,078 \mathrm{~b}$ & 10,5802 & \multirow{4}{*}{0,000} \\
\hline & İşçi & 33 & 6,2 & $16,121 a, b$ & 12,4694 & \\
\hline & $\begin{array}{l}\text { Serbest } \\
\text { meslek }\end{array}$ & 5 & 0,9 & $18 \mathrm{a}, \mathrm{b}$ & 7,7782 & \\
\hline & Ev hanımı & 415 & 78,3 & $21,436 a$ & 14,9957 & \\
\hline \multirow{4}{*}{$\begin{array}{c}\text { Baba } \\
\text { mesleği }\end{array}$} & Memur & 157 & 29,6 & $15,344 a, b$ & 11,5635 & \multirow{4}{*}{0,000} \\
\hline & $\begin{array}{c}\text { Çalışmıyo } \\
\mathbf{r}\end{array}$ & 9 & 1,7 & $20,556 a, b$ & 9,7097 & \\
\hline & İşçi & 260 & 49,1 & $21,873 a, b$ & 15,0821 & \\
\hline & $\begin{array}{l}\text { Serbest } \\
\text { meslek }\end{array}$ & 95 & 17,9 & $22,021 a, b$ & 16,5304 & \\
\hline \multirow[t]{3}{*}{$\begin{array}{c}\text { Anne } \\
\text { eğitimi }\end{array}$} & $\begin{array}{c}\text { Üniversit } \\
\text { e }\end{array}$ & 111 & 20,9 & $14,712 \mathrm{c}$ & 12,5592 & \multirow{3}{*}{0,000} \\
\hline & Lise & 155 & 29,2 & $18,961 b$ & 13,8122 & \\
\hline & İlkokul & 264 & 49,8 & $22,549 a$ & 15,125 & \\
\hline \multirow[t]{3}{*}{$\begin{array}{c}\text { Baba } \\
\text { eğitimi }\end{array}$} & $\begin{array}{c}\text { Üniversit } \\
\text { e }\end{array}$ & 146 & 28 & $15,315 b$ & 12,3365 & \multirow{3}{*}{0,000} \\
\hline & Lise & 175 & 33,6 & $20,229 a$ & 13,8508 & \\
\hline & İlkokul & 200 & 38,4 & $22,985 a$ & 15,9265 & \\
\hline
\end{tabular}

Anne eğitimi $(p<0,01)$ ve baba eğitimi ( $p<$ 0,001 ) ile çocuğun diş fırçalama sıklığı arasındaki ilişki istatistik olarak önemli bulunmuştur (Tablo 2). Haftada 1 diş fırçalama veya diş fırçalamamanın, ilkokul mezunu annelerin çocuklarında en fazla, üniversite mezunu annelerin çocuklarında ise en az olduğu görülmüştür. Diş fırçalamamanın, ilkokul mezunu babaların çocuklarında en fazla, üniversite mezunu babaların çocuklarında ise en az düzeyde olduğu bulunmuştur. Anne ve babanın eğitim düzeyleri ve çocuğun diş fırçalamaya başlama zamanı olguları arasındaki ilişki, istatistiksel olarak anlamlı bulunmuştur ( $p<0,001$ ) (Tablo 2). 0-2 yaş aralığında diş fırçalamaya başlayan çocukların oranının, ilkokul mezunu anne ve babaların çocuklarında düşük, üniversite mezunu anne ve babaların çocuklarında ise yüksek olduğu bulunmuştur.
Tablo 2. Anne ve baba eğitimine göre çocuğun diş fırçalama sıklı̆ı ve diş fırçalamaya başlama yaşı

\begin{tabular}{|c|c|c|c|c|c|c|c|c|}
\hline \multicolumn{2}{|c|}{ Firçalama sıklığı (\%) } & \multirow{2}{*}{\begin{tabular}{|c|} 
Günde 1 \\
$\begin{array}{c}109 \\
(\% 41,3)\end{array}$
\end{tabular}} & Günde & \multicolumn{2}{|c|}{2 Günde $3^{\text {taftad }} \begin{array}{c}1 \\
\end{array}$} & Hiç & Toplan & $m x^{2} / p$ \\
\hline \multirow{3}{*}{$\begin{array}{l}\text { Anne } \\
\text { eğitimi }\end{array}$} & İlkokul & & $\begin{array}{c}78 \\
(\% 29,5)\end{array}$ & $\begin{array}{c}8 \\
(\% 3)\end{array}$ & $\begin{array}{c}40 \\
\% 15,2)\end{array}$ & $\left(\begin{array}{c}29 \\
(\% 11)\end{array}\right.$ & $\mid \begin{array}{c}264 \\
\% 49,8)\end{array}$ & \\
\hline & Lise & $\begin{array}{c}76 \\
(\% 49)\end{array}$ & $\begin{array}{c}38 \\
(\% 24,5)\end{array}$ & $\begin{array}{c}6 \\
(\% 3,9)\end{array}$ & $\begin{array}{c}28 \\
\% 18,1\}\end{array}$ & $\begin{array}{c}7 \\
\% 4,5\end{array}$ & $\frac{155}{(29,2)}$ & \multirow[t]{2}{*}{$\begin{array}{l}k^{2}=23,06 \\
p<0,003\end{array}$} \\
\hline & Üniversite & $=\left(\begin{array}{c}65 \\
(\% 58,6)\end{array}\right.$ & $\begin{array}{c}26 \\
(\% 23,4)\end{array}$ & $\begin{array}{c}3 \\
(\% 2,7)\end{array}$ & $\begin{array}{c}17 \\
\% 15,3\end{array}$ & b (\%0 & $\mid \begin{array}{l}111 \\
(\% 20,9)\end{array}$ & \\
\hline \multirow{3}{*}{$\begin{array}{l}\text { Baba } \\
\text { eğitimi }\end{array}$} & İlkokul & $\begin{array}{c}78 \\
(\% 39)\end{array}$ & $\begin{array}{c}57 \\
(\% 28,5)\end{array}$ & $\mid \begin{array}{c}6 \\
(\% 3)\end{array}$ & $\begin{array}{c}33 \\
\% 16,5\end{array}$ & $(\% 13)$ & $\left|\begin{array}{c}200 \\
\% 38,4\end{array}\right|$ & \\
\hline & Lise & $\begin{array}{c}79 \\
(\% 45,1)\end{array}$ & $\begin{array}{c}50 \\
(\% 28,6)\end{array}$ & $\begin{array}{c}9 \\
(\% 5,1)\end{array}$ & $\begin{array}{c}29 \\
\% 16,6)\end{array}$ & $\begin{array}{c}8 \\
\% 4,6\end{array}$ & $\mid \begin{array}{c}175 \\
\% 33,6)\end{array}$ & \multirow[t]{2}{*}{$\begin{aligned} k^{2}=30,85 \\
\text { 6) } \\
p<0,000\end{aligned}$} \\
\hline & Üniversite & $=\begin{array}{c}86 \\
(\% 58,9)\end{array}$ & $\begin{array}{c}33 \\
(\% 22,6)\end{array}$ & $\begin{array}{c}2 \\
(\% 1,4)\end{array}$ & $\begin{array}{c}23 \\
\% 15,8\end{array}$ & $\begin{array}{c}2 \\
\% 1,4\end{array}$ & 4) $\begin{array}{c}146 \\
(\% 28)\end{array}$ & \\
\hline \multicolumn{2}{|c|}{$\begin{array}{c}\text { Diş fırçalamaya } \\
\text { başlama yaşı (\%) }\end{array}$} & $0-1$ yaş & $1-2$ yaş & $\begin{array}{l}2-3 \\
\text { yas }\end{array}$ & $\begin{array}{l}3-4 \\
\text { yaş }\end{array}$ & $\begin{array}{l}4-5 \\
\text { yas }\end{array}$ & Toplam & $x^{2} / p$ \\
\hline \multirow{3}{*}{$\begin{array}{l}\text { Anne } \\
\text { eğitimi }\end{array}$} & İlkokul & $\begin{array}{c}18 \\
(\% 7,7)\end{array}$ & $\begin{array}{c}36 \\
(\% 15,3)\end{array}$ & $\left(\begin{array}{c}86 \\
(\% 36,6)\end{array}\right.$ & $\begin{array}{c}70 \\
\% 29,8\end{array}$ & $\begin{array}{c}25 \\
\% 10,6\end{array}$ & $6\left(\begin{array}{c}235 \\
647,6)\end{array}\right.$ & \multirow{3}{*}{$\begin{array}{l}k^{2}=34,42 \\
p<0,000\end{array}$} \\
\hline & Lise & $\begin{array}{c}15 \\
(\% 10,1)\end{array}$ & $\begin{array}{c}39 \\
(\% 26,4)\end{array}$ & $\begin{array}{c}50 \\
(\% 33,8)\end{array}$ & $\begin{array}{c}32 \\
\% 21,6\end{array}$ & $\begin{array}{r}12 \\
\% 8,1\end{array}$ & $\mid \begin{array}{c}148 \\
(\% 30)\end{array}$ & \\
\hline & Üniversite & $=\mid \begin{array}{c}16 \\
(\% 14,4)\end{array}$ & $\begin{array}{c}38 \\
(\% 34,2)\end{array}$ & $\left(\begin{array}{c}39 \\
\% 35,1)\end{array}\right.$ & $\begin{array}{c}18 \\
\% 16,2\end{array}$ & $b(\% 0$ & $\mid \begin{array}{c}111 \\
\% 22,5)\end{array}$ & \\
\hline \multirow{3}{*}{$\begin{array}{l}\text { Baba } \\
\text { egitimi }\end{array}$} & İlkokul & $\begin{array}{c}13 \\
(\% 7,5)\end{array}$ & $\begin{array}{c}29 \\
(\% 16,7)\end{array}$ & $\begin{array}{c}59 \\
(\% 33,9)\end{array}$ & $\begin{array}{c}51 \\
\% 29,3\end{array}$ & $\begin{array}{r}22 \\
\% 12,6\end{array}$ & $6\left(\begin{array}{c}174 \\
635,9)\end{array}\right.$ & \multirow{3}{*}{$\begin{array}{l}x^{2}=36,06 \\
p<0,000\end{array}$} \\
\hline & Lise & $\begin{array}{c}14 \\
(\% 8,4)\end{array}$ & $\begin{array}{c}37 \\
(\% 22,2)\end{array}$ & $\begin{array}{c}54 \\
(\% 32,3)\end{array}$ & \begin{tabular}{|c|}
49 \\
$\% 29,3 x$
\end{tabular} & $\begin{array}{c}13 \\
\% \% 7,8\end{array}$ & $\begin{array}{c}167 \\
\% 34,4)\end{array}$ & \\
\hline & Üniversite & $\begin{array}{c}19 \\
(\% 13,2)\end{array}$ & $\begin{array}{c}45 \\
(\% 31,3)\end{array}$ & $\begin{array}{c}59 \\
(\% 41)\end{array}$ & $\begin{array}{c}19 \\
\% 13,2\end{array}$ & $\begin{array}{c}2 \\
\% 1,4\end{array}$ & \begin{tabular}{|c|}
144 \\
$+\% 29,7$ \\
$\% 2$
\end{tabular} & \\
\hline
\end{tabular}

Anne DMFT $(p<0,001)$ ve baba DMFT $(p<0,01)$ değerleri ile çocuğun dmfs değerleri arasındaki ilişki anlamlıdır (Tablo 3). Bu değerler istatistiksel düzeyde anlamlıık göstermiş olsa da, klinik olarak ele alındığında, bu değerin beklenenden daha düşük olduğu söylenebilir. dmfs değerleri ile anne diş fırçalama alışkanlığı $(p<0,001)$ ve baba diş fırçalama alışkanlığı $(p<0,01)$ arasındaki farklılıklar istatistiksel olarak anlamlı bulunmuştur (Tablo 4). Haftada 1 kez diş fırçalayan veya hiç diş fırçalamayan ebeveynlerin çocuklarının dmfs değerlerinin ise oldukça yüksek olduğu görülmektedir. Çalışmada, dmfs değerleri ile annenin diş ipi ve ağız gargarası kullanımı ve babanın diş ipi kullanımı ile dmfs değerleri arasındaki farklııklar, anlamlı bulunurken ( $p<0,001)$, babanın ağız gargarası kullanımı ile dmfs değeri arasındaki farklııı ise, istatistiksel düzeyde anlamlı bulunmamıştır ( $p>0,05)$ (Tablo 4). Ayrıca, diş ipi ve ağız gargarası kullanan ailelerin çocuklarında, dmfs değerlerinin daha düşük oldukları gözlenmiştir. dmfs değerleri ile babanın gingival ve oral hijyen indeks değerleri $(p<0,01)$, annenin gingival $(p<0,01)$ ve oral hijyen indeks değerleri $(p<0,05)$ arasındaki 
ilişki anlamlı bulunmuştur (Tablo 5). Oral hijyen ve gingival indeksleri 3 olan ebeveynlerin çocuklarında dmfs değerlerinin artmış oldukları gözlenmiştir.

Tablo 3. Anne ve babaların DMFT ve çocukların dmfs değerleri arasındaki ilişki

\begin{tabular}{cccc}
\hline & & \multicolumn{3}{c}{ DMFT } \\
& & Anne & Baba \\
\hline dmfs & Korelasyon &, $217^{* *}$ &, $171^{* *}$ \\
& $\begin{array}{c}\text { katsaylsI } \\
\text { p degeri }\end{array}$ & 0,000 & 0,007 \\
\hline
\end{tabular}

Tablo 4. Ebeveynlerin oral hijyen alışkanlıklarına göre ortalama dmfs değerleri

\begin{tabular}{|c|c|c|c|c|c|c|}
\hline \multicolumn{2}{|c|}{$\begin{array}{l}\text { Diş fırçalama } \\
\text { sıklığı }\end{array}$} & $\mathbf{N}$ & $\%$ & $\begin{array}{c}\text { Ortalama } \\
\text { dmfs }\end{array}$ & $\begin{array}{c}\text { Standart } \\
\text { Sapma }\end{array}$ & $\begin{array}{l}\text { p değeri } \\
(p<0,05)\end{array}$ \\
\hline \multirow[t]{5}{*}{ Anne } & Günde 3 & 19 & 3,6 & $16,632 \mathrm{~b}$ & 11,6486 & \multirow[t]{5}{*}{0,000} \\
\hline & Günde 2 & 179 & 33,8 & $16,642 \mathrm{~b}$ & 13,523 & \\
\hline & Günde 1 & 218 & 41,1 & $20,096 a, b$ & 14,5395 & \\
\hline & Haftada 1 & 93 & 17,5 & $25,720 a$ & 16,2443 & \\
\hline & Hic & 21 & 4 & $21,762 a, b$ & 8,3541 & \\
\hline \multirow[t]{5}{*}{ Baba } & Günde 3 & 7 & 1,3 & $15,143 \mathrm{~b}$ & 2,7946 & \multirow[t]{5}{*}{0,001} \\
\hline & Günde 2 & 73 & 14 & $17,233 a, b$ & 13,7967 & \\
\hline & Günde 1 & 238 & 45,7 & $18,29 a, b$ & 14,481 & \\
\hline & Haftada 1 & 125 & 24 & $23,032 \mathrm{~b}$ & 15,2733 & \\
\hline & Hiç & 78 & 15 & $22,782 a, b$ & 14,1289 & \\
\hline \multicolumn{7}{|c|}{ Diş ipi kullanımı } \\
\hline \multirow[t]{2}{*}{ Anne } & Evet & 75 & 14,2 & 16,133 & 15,5427 & \multirow[t]{2}{*}{0,002} \\
\hline & Hayır & 455 & 85,8 & 20,473 & 14,2958 & \\
\hline \multirow[t]{2}{*}{ Baba } & Evet & 48 & 9,2 & 13,188 & 12,7039 & \multirow[t]{2}{*}{0,000} \\
\hline & Hayır & 473 & 90,8 & 20,592 & 14,624 & \\
\hline \multicolumn{7}{|c|}{$\begin{array}{c}\text { Ağız gargarası } \\
\text { kullanımı }\end{array}$} \\
\hline \multirow[t]{2}{*}{ Anne } & Evet & 86 & 16,2 & 17,198 & 16,5101 & \multirow[t]{2}{*}{0,006} \\
\hline & Hayır & 444 & 83,8 & 20,374 & 14,0922 & \\
\hline \multirow[t]{2}{*}{ Baba } & Evet & 86 & 16,5 & 19,116 & 15,0289 & \multirow[t]{2}{*}{0,491} \\
\hline & Hayır & 435 & 3,5 & 20,067 & 14,5321 & \\
\hline
\end{tabular}

Tablo 5. Ebeveynlerin gingival indeks ve oral hijyen indeksi değerlerine göre ortalama dmfs değerleri

\begin{tabular}{|c|c|c|c|c|c|c|}
\hline \multicolumn{2}{|c|}{$\begin{array}{c}\text { Gingival } \\
\text { indeks }\end{array}$} & $\mathbf{N}$ & $\%$ & $\begin{array}{l}\text { Ortalama } \\
\text { dmfs }\end{array}$ & $\begin{array}{c}\text { Standart } \\
\text { Sapma }\end{array}$ & $p$ değeri $(p<0,05)$ \\
\hline \multirow{4}{*}{ Anne } & 0 & 45 & 9,7 & $14,289 a$ & 11,5554 & \multirow[t]{4}{*}{0,005} \\
\hline & 1 & 307 & 66,3 & $20,612 a, b$ & 15,1082 & \\
\hline & 2 & 94 & 20,3 & $20,000 a, b$ & 13,9191 & \\
\hline & 3 & 17 & 3,7 & $24,824 b$ & 12,9915 & \\
\hline \multirow[t]{4}{*}{ Baba } & 0 & 9 & 3,7 & $8,000 a$ & 15,3623 & \multirow[t]{4}{*}{0,001} \\
\hline & 1 & 83 & 33,7 & $19,133 b$ & 15,1342 & \\
\hline & 2 & 88 & 35,8 & $20,693 \mathrm{~b}$ & 14,7752 & \\
\hline & 3 & 66 & 26,8 & $22,333 b$ & 13,6982 & \\
\hline \multicolumn{2}{|c|}{$\begin{array}{c}\text { Oral } \\
\text { hijyen } \\
\text { indeksi }\end{array}$} & & & & & \\
\hline Anne & $\mathbf{0}$ & 44 & 9,5 & $14,295 a$ & 11,689 & \multirow[t]{4}{*}{0,012} \\
\hline & 1 & 291 & 62,9 & $20,546 a, b$ & 14,9572 & \\
\hline & 2 & 106 & 22,9 & $20,575 b$ & 14,5896 & \\
\hline & 3 & 22 & 4,8 & $22,000 \mathrm{~b}$ & 13,227 & \\
\hline \multirow[t]{4}{*}{ Baba } & 0 & 9 & 3,7 & $8,000 a$ & 15,3623 & \multirow[t]{4}{*}{0,001} \\
\hline & $\mathbf{1}$ & 69 & 28 & $18,899 \mathrm{~b}$ & 14,6409 & \\
\hline & 2 & 98 & 39,8 & $20,959 b$ & 15,3897 & \\
\hline & 3 & 70 & 28,5 & $21,786 \mathrm{~b}$ & 13,453 & \\
\hline
\end{tabular}

\section{TARTIŞMA}

Son 20 yılda yapılan epidemiyolojik çalışmalarda, farklı sosyal sınıfların, çürük deneyimlerinin de farklı olduğu görülmektedir. ${ }^{10,11}$ Beş yaşında 324 çocuğun değerlendirildiği bir çalışmada, çürük oluşumunda sosyo-ekonomik durumun, diş fırçalama alışkanlığından 2 kat daha fazla etkili olduğu görülmüştür. ${ }^{12}$ EÇÇ'nin düşük sosyoekonomik seviyeye sahip ailelerin çocuklarında daha sık görüldüğünü bildiren çalışmalarda ${ }^{13-22}$ bu durum; uygun olmayan beslenme alışkanlıkları ${ }^{15-19,23-26}$, anneden ve bakıcıdan çocuğa bakteri geçişinin fazlalığı, ${ }^{17}$ uygun olmayan biberon kullanımı, ${ }^{27}$ diş fırçası ve macunu eksikliği, diş hekimine gitme sıklığının daha düşük olması, ${ }^{19,23,24,27}$ koruyucu diş hekimliği uygulamalarının yetersiz olmaSı, ${ }^{16,17}$ hamilelikte geçirilen hastalıklar, düşük doğum ağırlıklı bebeklerin yüksek sayıda olmaları, malnütrisyon gibi durumlara bağlı süt dişlerinde sıklıkla hipoplazi görülmesi, ${ }^{28}$ kadercilik ve bulundukları topluma ilişkin dezavantajlar ${ }^{14,17}$ ile ilişkilendirilmiştir. Diğer taraftan, yapılan bir çalışmada, yüksek sosyo-ekonomik duruma sahip bireylerde, rafine karbonhidratların daha fazla tüketilmesine bağı olarak daha fazla sayıda diş çürükleri bulunduğu da gösterilmiştir. ${ }^{29,30}$ Sosyoekonomik seviyenin belirlenmesinde; eğitim, gelir ve meslek durumunu temel alan çalışmalar bulunmaktadır. 22,31,32 Çalışmamızda da sosyoekonomik durumun incelenmesinde bu değişkenler incelenmiştir.

Ailelerin oral hijyen, beslenme ve diş bakımı konusunda yeterli düzeyde bilgi sahibi olmalarının, EÇÇ'ye karşı koruyucu bir faktör oluşturacağı bildirilmiştir. ${ }^{10,33}$ Eğitim seviyesi yüksek olan ailelerin oral hijyen konusunda daha bilgili oldukları bildirilmiştir. Bu durumda, bilgiye daha kolay erişmeler, ${ }^{22,31,32}$ oral hijyen alışkanlığı farkındalıklarının daha fazla olması, ${ }^{34}$ çocuklarının diş fırçalama ve diyet alışkanlıklarına daha önem vermeleri' ${ }^{23,35,36}$ ile ilişkilendirilmiştir. Eğitim seviyesi düşük annelerin büyük çoğunluğunun ise; hamilelik sırasında uygulanması gereken ağız bakımı, doğum sonrası bebeğin ağız temizliği ve bebeğin ilk diş hekimi kontrolüne ne zaman götürülmesi gerektiği konusundaki bilgileri yetersiz bulunmuştur. ${ }^{10,33}$

Eğitim seviyesi yüksek olan ailelerin çürük prevelansının daha $a z^{32,36,37}$ ve dmft değerlerinin daha düşük ${ }^{23,38}$ olduğu görülmüştür. Çalışmamızda da, ebeveynlerin eğitim seviyeleri arttıkça, dmfs değerlerinin azaldığı, başlama sıklığının arttığı ve fırçalamaya başlama yaşının düştüğü tespit edilmiştir. İncelenen hasta grubumuzda, çalışmayan ve ilkokul mezunu olan 
annelerin sayılarının da oldukça fazla olduğu saptanmıştır. Ebeveynlerin mesleği hem gelir hem de eğitim seviyesi ile yakından ilişkilidir. Aylık geliri yüksek olan ailelerin çocuklarında en düşük dmfs değerleri görülmüştür. Ebeveynleri memur olan çocukların dmfs değerleri daha düşük bulunurken, ebeveynlerin çalışmadığı ailelerin çocuklarında ise dmfs değerlerinin yüksek oldukları gözlenmiştir. Ancak, Kırzıoğlu ve ark. (2002), Isparta, Erzurum ve Bursa İlleri'nde yaptıkları bir çalışmada, en fazla çürük gelişiminin lise mezunu anne ve babalarda söz konusu olduğunu gözlemlemişlerdir. Çalışmada, yüksekokul bitirmiş olan babaların çocuklarında çürük mevcudiyeti daha az, yüksekokul bitirmiş olan annelerin çocuklarında ise çürük mevcudiyeti daha fazla bulunmuştur. Bu durum annelerin çalışıyor olması ve bu sebeple çocuklarıyla hem yeteri kadar ilgilenememeleri ve hem de çocuklarda herhangi bir diyet düzenlemesi yapamamaları ile ilişkilendirilmiştir. ${ }^{39}$ Ayrıca Çin'de 2-4 yaşlarında bulunan 426 çocuğun katıldığı bir çalışmada, aile geliri ve çürük prevalansı arasında belirgin bir ilişki bulunamamıştır. Bu durumun sebebi; çalışmaya katılan grupların homojen dağılmamış olmaları ve çalışmaya dahil edilen örneklem sayısının düşük olması ile açıklanmıştır. ${ }^{40}$

Ebeveynlerin çocukları için en önemli rol model olduğunu, bu nedenle oral hijyen alışkanlarının, çocukta benzer şekilde geliştiğini görülmüştür. ${ }^{41-43}$ Annelerin diş fırçalama alışkanlıklarının, çocukların çürük deneyimleri ile yakından ilişkili olduğu bildirilmiştir. ${ }^{11,14}$ Diğer bir çalışmada da, anneler gibi babaların da çürük hikayelerinin ve sahip oldukları oral hijyen alışkanlıklarının, çocuklarda görülen EÇÇ oranları ile yakından ilişkili olduğu gösterilmiştir. ${ }^{2,45}$ Annelerde ve çocuklarında mevcut olan diş çürükleri arasındaki ilişkinin, pozitif korelasyon gösterdiğini tespit etmişlerdir. ${ }^{10,41}$ Annelerin ağızlarında tedavi edilmemiş diş çürüklerinin bulunması, çocuklarında da çürük görülme olasılığını arttırmaktadır. ${ }^{10,14}$

Çalışmamızda çocukların dmfs değerleri ile, ebeveynlerin oral hijyen alışkanlıkları arasında istatistiksel farklılıklar anlamlı düzeyde bulunurken, sadece babaların gargara kullanımı istatistiksel olarak önemli bulunmamıştır. Diş ipi ve gargara kullanan ailelerin çocuklarında dmfs değeri düşük bulunurken, dmfs ile ebeveynlerin DMFT değerleri arasındaki ilişkiler ise pozitif korelasyon göstermişlerdir. Babaların gargara kullanımı, oral hijyen durumunun belirlenmesinde tek başına bir belirleyici olmadığından, çalışmamızda istatistiksel olarak önemli bulunmadığı düşünülmüştür.
Gingival ve oral hijyen indeksi yüksek olan ebeveynlerin çocuklarında, dmfs değerlerinin arttığı tespit edilmiştir. Ebeveynlerin kendi ağız ve diş sağlıklarına verdikleri önemin çocuklarına yansıdığı görülmektedir. Ebeveynlerin oral hijyen bilgileri ve alışkanlıkları, çocuklarında da zaman içerisinde benzer alışkanlıklara dönüşmektedir. Ayrıca oral hijyeni iyi olan ailelerde, aile içi geçiş etkisinin azalması, bu ailelerin çocuklarının da dmfs değerlerinin düşük olmasını sağlamaktadır.

\section{SONUÇ}

Çalışmanın sonuçları düşük sosyo-ekonomik seviyedeki çocuklarda diş çürüklerinin önlenmesinin, yüksek sosyo-ekonomik seviyedeki çocuklar kadar başarılı olmadığını göstermektedir. Çocukların rol model olarak aldıkları ebeveynlerinin oral hijyen alışkanlıklarının, çocukların alışkanlıklarının da şekillenmesi üzerinde oldukça önemli olduğu düşüncesine varılmıştır. Düşük sosyoekonomik grupta daha etkili çürük önleme stratejilerine ihtiyaç duyulmaktadır.

NOT: Çalışmada herhangi bir yazar, kurum ya da kurulus ile çıkar çatışması içerisinde bulunmamaktadır. Makale daha önce hiçbir yerde yayınlanmamış ve yayınlanmak üzere işlem görmemektedir

\section{KAYNAKLAR}

1. Ismail AI, Sohn W. A systematic review of clinical diagnostic criteria of early childhood caries. J Public Health Dent 1999;59:171-91.

2. Ivančević $V$, Tušek I, Tušek J, Knežević M, Elheshk $\mathrm{S}$, Luković I. Using association rule mining to identify risk factors for early childhood caries. Comput Methods Programs Biomed 2015;122:17581.

3. EzEldeen M, Gizani S, Declerck D. Long-term outcome of oral health in patients with early childhood caries treated under general anaesthesia. Eur Arch Paediatr Dent 2015;16:33340.

4. Fontana M. The clinical, environmental, and behavioral factors that foster early childhood caries: evidence for caries risk assessment. Pediatr Dent 2015;37:217-25.

5. Nakayama $Y$, Mori $M$. Association between nocturnal breastfeeding and snacking habits and the risk of early childhood caries in 18-to 23month-old Japanese children. J Epidemiol 2015;25:142-7. 
6. Tinanoff N, Baez RJ, Diaz Guillory C, Donly KJ, Feldens CA, McGrath C, Phantumvanit P, Pitts NB, Seow WK, Sharkov N, Songpaisan Y, Twetman S. Early childhood caries epidemiology, aetiology, risk assessment, societal burden, management, education, and policy: Global perspective. Int J Paediatr Dent 2019;29:238-48.

7. Ismail AI. Determinants of health in children and the problem of early childhood caries. Pediatr Dent 2003;25:328-33.

8. Löe $\mathrm{H}$. The gingival index, the plaque index and the retention index systems. J Periodontol 1967;38:610-6.

9. Greene JG, Vermillion JR. The simplified oral hygiene index. J Am Dent Assoc 1964;68:7-13.

10. de Souza P, Proença MAM, Franco MM, Rodrigues VP, Costa JF, Costa EL. Association between early childhood caries and maternal caries status: A cross-section study in São Luís, Maranhão, Brazil. Eur J Dent 2015;9:122-6.

11. Azevedo M, van de Sande F, Maske T, Signori C, Romano A, Cenci $M$. Correlation between the cariogenic response in biofilms generated from saliva of mother/child pairs. Biofouling 2014;30:903-9.

12. Schou L, Uitenbroek D. Social and behavioural indicators of caries experience in 5-year-old children. Community Dent Oral Epidemiol 1995;23:276-81.

13. dos Santos Junior VE, de Sousa RMB, Oliveira MC, de Caldas Junior AF, Rosenblatt A. Early childhood caries and its relationship with perinatal, socioeconomic and nutritional risks: a crosssectional study. BMC Oral Health 2014;14:1-5.

14. Dye BA, Vargas CM, Lee JJ, Magder L, Tinanoff N. Assessing the relationship between children's oral health status and that of their mothers. J Am Dent Assoc 2011;142:173-83.

15. Seow W, Clifford H, Battistutta D, Morawska A, Holcombe T. Case-control study of early childhood caries in Australia. Caries Res 2009;43:25-35.

16. Early Childhood Caries: IAPD Bangkok Declaration. Int J Paediatr Dent 2019;29:384-6.

17. Fontana $M$, Jackson R, Eckert G, Swigonski N, Chin J, Zandona AF, Ando M, Stookey GK, Downs S, Zero DT. Identification of caries risk factors in toddlers. J Dent Res 2011;90:209-14.

18. Majorana A, Cagetti MG, Bardellini E, Amadori F, Conti G, Strohmenger L, Campus G. Feeding and smoking habits as cumulative risk factors for early childhood caries in toddlers, after adjustment for several behavioral determinants: a retrospective study. BMC pediatrics 2014;14:1-8.

19. Borutta A, Wagner M, Kneist S. Early childhood caries: A multi-factorial disease. OHDMBSC 2010;9:32-8.

20. Plutzer K, Keirse M. Incidence and prevention of early childhood caries in one-and two-parent families. Child Care Health Dev 2011;37:5-10.

21. van Palenstein Helderman W, Soe W, Van't Hof M. Risk factors of early childhood caries in a Southeast Asian population. J Dent Res 2006;85:85-8.

22. Zhou Y, Yang J, Lo E, Lin H. The contribution of life course determinants to early childhood caries: a 2-year cohort study. Caries Res 2012;46:87-94.

23. Jain $M$, Namdev R, Bodh M, Dutta $S$, Singhal $P$, Kumar A. Social and behavioral determinants for Early Childhood Caries among preschool children in India. J Dent Res Dent Clin Dent Prospects 2015;9:115-20.

24. Du M, Luo Y, Zeng X, Alkhatib N, Bedi R. Caries in preschool children and its risk factors in 2 provinces in China. Quintessence Int 2007;38:14351.

25. Nunes AMM, da Silva AAM, Alves CMC, Hugo FN, Ribeiro CCC. Factors underlying the polarization of early childhood caries within a high-risk population. BMC Public Health 2014;14:1-9.

26. Winter J, Glaser $M$, Heinzel-Gutenbrunner $M$, Pieper K. Association of caries increment in preschool children with nutritional and preventive variables. Clin Oral Investig 2015;19:1913-9.

27. Seow W, Clifford H, Battistutta D, Morawska A, Holcombe T. Case-control study of early childhood caries in Australia. Caries Res 2009;43:25-35.

28. Li Y, Wang W. Predicting caries in permanent teeth from caries in primary teeth: an eight-year cohort study. J Dent Res 2002;81:561-6.

29. Hayden C, Bowler JO, Chambers S, Freeman R, Humphris G, Richards D, Cecil JE. Obesity and dental caries in children: a systematic review and meta-analysis. Community Dent Oral Epidemiol 2013;41:289-308.

30. Olatosi O, Inem V, Sofola O, Prakash P, Sote E. The prevalence of early childhood caries and its associated risk factors among preschool children referred to a tertiary care institution. Niger J Clin Pract 2015;18:493-501.

31. Al-Hosani E, Rugg-Gunn A. Combination of low parental educational attainment and high parental 
income related to high caries experience in pre-school children in Abu Dhabi. Community Dent Oral Epidemiol 1998;26:31-6.

32. Feldens C, Giugliani E, Vigo A, Vítolo M. Early feeding practices and severe early childhood caries in four-year-old children from southern Brazil: a birth cohort study. Caries Res 2010;44:445-52.

33. Singh A, Gambhir RS, Singh S, Kapoor V, Singh J. Oral health: How much do you know?-A study on knowledge, attitude and practices of patients visiting a North Indian dental school. Eur J Dent 2014;8:63-7.

34. Wong M, Lu HX, Lo E. Caries increment over 2 years in preschool children: a life course approach. Int J Paediatr Dent 2012;22:77-84.

35. Tulunoğlu Ö, Bodur $H$, Akal $N$. Aile eğitim düzeyinin okul öncesi çocuklardaki ağız diş sağlığı uygulamaları üzerine etkisinin değerlendirilmesi. Acta Odontologica Turcica 1999;16:27-32.

36. Namal N, Vehit H, Can G. Risk factors for dental caries in Turkish preschool children. J Indian Soc Pedod Prev Dent 2005;23:115-8.

37. Namal N, Yuceokur A, Can G. Significant caries index values and related factors in 5-6-year-old children in Istanbul, Turkey. East Mediterr Health J 2009;15:178-84.

38. Ersin NK, Eronat N, Cogulu D, Uzel A, Aksit S. Association of maternal-child characteristics as a factor in early childhood caries and salivary bacterial counts. J Dent Child (Chic) 2006;73:10511.

39. Kırzıoğlu Z, Gürbüz T, Şimşek S, Yağdıran A, Karatoprak O. Erzurum, Bursa ve Isparta illerinde, 2-5 yaş grubu çocuklarda çürük sıklı̆ı ve bazı risk faktörlerinin değerlendirilmesi. Atatürk Üniv Diş Hek Fak Derg 2002;12:6-13.

40. Du M, Guo L, Holt R, Champion J, Bedi R. Caries patterns and their relationship to infant feeding and socio-economic status in 2-4-year-old Chinese children. Int Dent J 2000;50:385-9.

41. Retnakumari N, Cyriac G. Childhood caries as influenced by maternal and child characteristics in pre-school children of Kerala-an epidemiological study. Contemp Clin Dent 2012;3:2-8.

42. Finlayson TL, Siefert $K$, Ismail AI, Sohn W. Maternal self-efficacy and 1-5-year-old children's brushing habits. Community Dent Oral Epidemiol 2007;35:272-81.
43. Meyer F, Enax J. Early Childhood Caries: Epidemiology, Aetiology, and Prevention. Int J Dent 2018;22:1-7.

44. Prakasha Shrutha S, Vinit GBG, Giri KY, Alam S. Feeding practices and early childhood caries: $A$ cross-sectional study of preschool children in Kanpur district, India. ISRN Dent 2013;2013:1-6.

45. Mattila M-L, Rautava $P$, Sillanpää M, Paunio P. Caries in five-year-old children and associations with family-related factors. J Dent Res 2000;79:875-81.

\section{Yazışma Adresi}

Dr. Öğr. Üyesi Tuğba Yiğit

Uşak Üniversitesi Diş Hekimliği Fakültesi, Pedodonti Anabilim Dalı, Uşak

Tel: 02762212231

Fax: 02762212232

e-posta: tugba.yigit@usak.edu.tr 